\title{
Integrity of Scientific Data: Transparency of Clinical Trial Data
}

\author{
Nicholas Moore ${ }^{1}$, Yves Juillet ${ }^{2}$, Pierre-Henri Bertoye ${ }^{3}$ and the participants in Round Table $N^{\circ} 4$, Giens XXII \\ 1 Département de Pharmacologie, Université de Bordeaux, Bordeaux, France \\ 2 Les Entreprises du Médicament, Paris, France \\ 3 Agence Française de Sécurité Sanitaire des Produits de Santé, Afssaps, Saint Denis, France
}

\begin{abstract}
Keywords: clinical trials; fraud; malpractice; prevention; management

Abstract - The integrity of the data from clinical trials and of its use is an essential element of the scientific method, and of the trust one can have in this method. There are many examples of fraud, and they recur regularly. The objective of this round table was to work on the definition of fraud, on its recognition and prevention especially in the institutional system. Fraud involves an active decision to cheat, and ranges from trying to hide incompetence to wholesale invention of data, patients or studies. Its frequency is difficult to evaluate but might be as high as $1 \%$ of all studies or publications. Fraud can involve ethics (post-hoc IRB [institutional review board] approval, IRB requests not applied, lack of consent), or any of the steps from realisation to interpretation of studies or trials. Identification of fraud is made harder by the usual risk for the whistleblowers, who must be protected. Seeking fraud is implicit in Good Clinical Practices (GCP) that all industry sponsors must apply, but that are less often applied by institutional sponsors. It might be useful to install procedures to detect fraud in studies, especially institutional. Various statistical methods can be used to identify unusual data patterns that could suggest fraud. Once fraud is identified, its management is often not foreseen. Here again, clear procedures or recommendations would be of help.
\end{abstract}

"On a rainy afternoon in June, Eric Poehlman stood before a federal judge in the United States District Court in downtown Burlington, Vt. His sentencing hearing had dragged on for more than four hours, and Poehlman, dressed in a black suit, remained silent while the lawyers argued over the appropriate sentence for his transgressions. Now was his chance to speak. A year earlier, in the same courthouse, Poehlman pleaded guilty to lying on a federal grant application and admitted to fabricating more than a decade's worth of scientific data on obesity, menopause and aging, much of it while conducting clinical research as a tenured faculty member at the University of Vermont. He presented fraudulent data in lectures and in published papers, and he used this data to obtain millions of dollars in federal grants from the National Institutes of Health - a crime subject to as many as five years in federal prison. Poehlman's admission of guilt came after more than five years during which he denied the charges against him, lied under oath and tried to discredit his accusers. By the time Poehlman came clean, his case had grown into one of the most expansive cases of scientific fraud in U.S. history." (from

\footnotetext{
^ For a list of participants, please see the end of the article.
}

"An unwelcome discovery", Jeneen Interlandi, New York Times, 22 October 2006).

A few years before, one of his technicians/students noticed that data he had analysed some time before had changed, and that initially negative results had become positive. He tried to understand what had happened and confronted his boss, who threatened to sack him. He talked to a colleague, who advised him to document everything carefully. Then he saw the University administration. The investigation lasted 5 years, and showed consistent, systematic and repeated fraud, that threw down all the research on menopause and obesity, a dozen papers in the best journals. It appeared that the fraud had been initiated to change results that did not confirm the original hypothesis of which the investigator was convinced, and which was biologically plausible. Unusually, the whistleblower was not fired, but his lab was closed and he became jobless anyhow. Eric Poehlmann is in prison.

In this exemplary case like in many others (rarely as big), it's an assistant or a colleague who questions results, and discovers the fraud. Beyond the opprobrium on the fraudulent researcher, and the common destruction of the whistle-blower's career, ${ }^{[1]}$ fraud 
causes prejudice to others whether they are in the same team, or use the fraudulent results. Fraud can also cause distant damage, because when fraudulent programs are financed others that might have been aren't. In addition, other preclinical or clinical research leads can be abandoned for lack of financing or because they go against the fraudulent results. Finally fraud discredits honest research. ${ }^{[2]}$

Fraud in research is as old as research itself, and has been the object of many books. ${ }^{[3-5]}$ Fraud can taint industrial ${ }^{[6]}$ as well as academic research. ${ }^{[7,8]}$ Each day bring its lot of examples of fraud, published in the general press, and each new case damages all persons involved and research itself. ${ }^{[9]}$

Fraud, and the ways of identifying and treating it are the subject of this round table, justified by these recent examples of scientific fraud.

\section{Definitions and context}

Fraud is an act of bad faith, done in contradiction with law or regulations, and to the detriment of others. it is intentional, which excludes incompetence, which isn't.

The magnitude of the problem is difficult to assess for lack of precise data. Visible or publicly known fraud represent about $1 \%$ of all research or publications. ${ }^{[10]}$ About $50 \%$ of the cases of suspect fraud are confirmed. ${ }^{[11]}$ A constant feature is the risk taken by the whistleblower, which brings us to our first recommendation: protect the whistleblower: (i) the initial constatation must be factual and documented; (ii) reporting of suspect fraud should be made mandatory through regulation.

The round table did not consider conflicts of interest or study protocols that are voluntarily developed to produce biased results. ${ }^{[12]}$

\section{Ethics fraud}

These are faked or post-hoc IRB opinions, faked consent forms or signatures, changes required by ethics committees that are presented as done when in fact they haven't...

Two main categories of ethics fraud have been identified.

(a) Post-hoc or falsified ethics committees advice. This concerns mainly observational studies that in France do not require committee for the protection of persons (CPP) approval. Journals usually require Institutional review board approval, which authors interpret as requiring CPP approval. Though it is fraud stricto sensu, there is no lack of consent or hidden risk for the patients.

The recommendation is to obtain recognition by journal editors of the other independent review boards that assess noninterventional research that does not requires CPP approval: the
Scientific Committees that decide to finance the research, the National data protection committee, the national professional committee that ensures investigator ethics, ... since all these committees are independent from the investigator.

(b) Cases where effectively the CPP's recommendations and requirement have not been followed, or patients did not provide consent. There is a direct fault concerning ethics, consent or patient protection.

What should be done in the case of a breach of ethics?

- inform other investigators and the sponsor in multicentre studies;

- inform other CPP if the CPP of the investigator's region are not the that of the main investigator. The fraudulent investigator might be involved in other studies that would then require scrutiny for possible fraud.

What should be done with the fraudulent data? When they are scientifically valid, should they be systematically rejected?

Two situations were identified resulting in a recommendation:

- if the non-ethical data can be clearly circumscribed, the analysis should be done with and without the non-ethical data, and the results compared;

- if these data cannot be isolated, should the study as a whole be discarded, or used (with controlled access) while mentioning their non-ethical nature, especially when the study cannot be repeated and the results can have important public health consequences (AIDS for instance);

- in all cases, initiate legal procedure against the persons responsible for the study and the ethical breaches.

\section{Fraud in the data and results of clinical trials}

These can be divided into fraud concerning data acquisition and fraud in their analysis (especially statistical).

Identification and management of data fraud is usually the domain of GCP monitoring of clinical trials, and usually the fraudulent data are removed from the study analysis.

A second type of fraud is statistical fraud, and especially statistical analysis that is orientated for specific results. It may also happen that for various reasons interim analyses may give different results from final analysis. This may be queried and require validation. It is therefore necessary to be able to reproduce the different statistical stages that produced the different results.

\section{Recommendation:}

- have a formal statistical analysis that is dated, traceable with dates of amendments;

- archive a copy of the database at the time of each interim analysis, so it can be reproduced if need be. 


\section{Detection of fraud}

A study has many actors, and controls need to be developed along the whole production process, from conception to publication. The sponsor/CRO [contract research organisation], quality control by study monitors, audit, regulatory authorities, including inspection services, the investigators and collaborators, statisticians, journals, referees, co-authors, readers. ${ }^{[13]}$ Each of these may be involved in detection of fraud, as shown in the past.

If looking for fraud or misconduct is part of the daily activity of industrial sponsors, and of the regulatory authorities that inspect and review studies submitted for registration of new drugs, This is less often the case for studies with institutional sponsorship, whose sponsor is the hospital or other scientific organisations. The institutional sponsor has often not measured the existence of the problem or doesn't have the means to confront it (figure 1), especially if the suspect investigator is an opinion or community leader. These spurious studies may result in publications in high-level journals which may disrupt the scientific fields concerned.

Typically identification of fraud is done through monitoring and audit. It could also be achieved through statistical analysis, especially of between-centre discrepancies in multicentre trials. ${ }^{[13,14]}$ In certain cases (electronic case report forms [CRF], eCRF or iCRF), changes in data entries suggest fraud: an audit trail of all entries should be kept.

Academic or institutional research is often ignorant of advanced fraud detection methods.

Recommendations:

adequation of means and methods to the risk of fraud:

- targeted monitoring;

- intercentre coherence indicators (multicentre studies);

- electronic CRF audit trails;

- development of a guide to fraud detection.

\section{Signal processing investigation and demonstration of fraud}

Once the fraud is suspected, it must be investigated to demonstrate its reality or on the opposite discard the suspicion : an unresolved suspicion remains a potential blemish. The investigation should not unnecessarily put the suspect's reputation at risk, without excessively protecting of a guilty investigator. There is little experience of these processes. It is not easy for an institution to investigate its own members, and the risk of conflicts of interest are great. It would be useful for there to be standardised procedures describing the processing of a signal of suspect or demonstrated fraud, and to manage the process in the most objective way possible so that suspects are guaranteed presumption of innocence during the investigation. At best there could be an independent investigative entity that could do these investigations at the request of the institution.

Recommendation:

- institute a National Bureau for Research Integrity, that could be assist research institutions in the prevention of fraud and in the processing of a signal of possible fraud.

\section{Management of fraud}

Once fraud is very suspect or demonstrated, what should be done with the fraudulent researcher? Should the case be treated by the university, the hospital, the Drug Agency, Justice, professional Orders, IRBs, Industry? Or all, and in what order?

When fraud is demonstrated the need for and level of intervention (professional or judiciary) is not always clearly apprehended by the institution which often hesitates between the wish of using the example for prevention and the fear of scandal. Some industrials may prefer simply to exclude the investigator from further contracts. In a more general manner, as above, it would be best that a clear judiciary decision on the reality or not of the fraud be made. Again there is a need for clear instructions on the shared management of this risk.

Recommendation:

- common and public procedures to manage proven fraud;

- this also relates to point 1 requiring mandatory administrative reporting of suspect fraud.

\section{Prevention of fraud}

\section{1. The personal medical file}

The personal shared medical file, and the national health insurance records could register and document patient participation in a trial, and the nature and dates of the various visits and procedures. Beyond safety aspects, preventing simultaneous participation in several trials, this will also document patient participation in the trial. Recording of visits and procedures will ensure the reality of the trial activities and compliance, to detect possible discrepancies with the case report forms or reported visit dates and content. This will also enable the recording of this research activity in the investigator's or other health professional's activity log. This could only be done with the patient's explicit approval.

Recommendation:

- include trial data in the Shared Personal Medical File. 
a) When the Hospital is sponsor of a study, has a systematic monitoring process been put in place, with an evaluation of the risk of fraud or malpractice?

b) Are your statisticians trained to detect fraud?

No 22/23

Yes $1 / 23$

« it's part of their job definition »

c) Is there specific investigator training on fraud in clinical trials ?

No $22 / 23$

but often reminders on the legal dispositions upon project initiation

d) How many cases of fraud have you detected over the last 5 years ?

19: 0 fraud ; 4: 1-4 frauds; 1: 20\% minor deviations

e) when fraud is detected and proven, what do you do ?

- nothing?

- warn against repeat fraud?

- blacklist?

- inform the hospital board/university/professional jurisdiction?

- Sue the investigator?

- depends

\section{2}

11 : not applicable

\section{Comment : Most hospitals estimate they don't have the means to act.}

Fig. 1. Results of a survey of French Public University Hospitals concerning fraud. Questions on the left, answers in bold. 23 of 31 hospitals answered.

\subsection{Training of trial personnel}

A share of fraud come from lack of training of investigators and others involved in research, who after a methodological or technical error might be tempted to turn to fraud to mask or compensate for this error. ${ }^{[15,16]}$ All efforts must be done to improve quality through training. ${ }^{[17]}$ Training will also increase sensitivity to fraud and its detection by co-investigators, or by critical reading...

This training exists, but is it used?

A minimal common core training curriculum should be defined, including specific training of future investigators, as an integral part of basic training, along with training in critical reading, and specific and adapted complementary training courses : (i) specialized training Masters, National CRA [clinical research assistant] and Investigator diplomas; (ii) continuing education validated by evaluation of professional practices.

This training should concern all persons involved in clinical trials, and not only the main investigator, each at his/her own level, for the investigator team (study nurses, CRA, technicians, pharmacists, ...) and for the sponsor group. Typically these should be harmonized within and between regions.
Recommendation:

- definition of a core curriculum for all actors of clinical research, for initial and continued education;

- training not only of main investigators, but of the whole research team;

- use of simulated cases as a training instrument.

\section{Legal aspects}

In general, the legal resources to prosecute the authors of fraud in France can rely on administrative (civil) law or penal law (penal code, public health code, professional deontology codes). Public Health law has specific indications for this situation (lack of consent for instance), whereas penal law is non-specific: the actions can come under the chapter on fraud or use of false documents, swindling for the main culprit, aiding and abetting after the fact for those who knew but did not report.

Sanctions are prison time, fines, striking from the rolls of authorized practitioners, that range from for instance 5 years in prison and a $375000 €$ fine for fraud to 3 years in prison and 


\begin{abstract}
Questions to journal editors:
do you give instructions to referees concerning the detection of fraud?

do you offer help (e.g., statistical) to referees for fraud detection?

how many suspect/demonstrated frauds do you identify each year

what happens when you identify a fraud?

$$
\begin{aligned}
& \text { quietly decline publication } \\
& \text { start legal procedures } \\
& \text { inform regulators } \\
& \text { inform other journal editors of possible fraud }
\end{aligned}
$$
\end{abstract}

do you have a systematic in-house process to identify possible fraud?

No

if needed?

from none in 15 years to 1 per year to 10 in 1500 papers per year

Other

\title{
Decline publication; Inform university
}

is there a blacklist of authors with suspect/demonstrated fraud?

No; vigilance on submissions by same author

\section{Comment : most frauds detected concern plagiarism, duplicate publications or theft.}

Fig. 2. Answers to a survey of journal editors, of whom about a dozen answered including very high level journals, and more modest speciality journals. Journal names are not given because most responses were in confidence.

$45000 €$ for lack of patient consent. The same fault can be prosecuted in different ways, and a careful legal opportunity analysis can help define the best strategy.

Whatever the legal recourse used, the judgment must be made public: ${ }^{[18]}$ a temporarily disbarred physician could decide to "sail around the world" and thereby mask the judgment and sentence.

Recommendation:

- publicity of judgment, publication on official sites of the sentences.

\section{Publication fraud}

Finally, the main causes of fraud are lucrative (fraud in industry-sponsored trials), search for glory (academic research), both being non-exclusive. Academic (and industrial) research will often result in a publication, and it is the desire to improve the probability of a paper being accepted in a better journal that will often be the initial motive of the fraud. The fraud may therefore have, through the publication of fraudulent results an impact on the whole research environment, which could rely on the faked results to develop ulterior actions or strategies especially in public health.

Publication therefore has a double importance in fraud : as a place where fraud can be detected, and as a victim of fraudulent activities. It is important to ensure that once fraud is detected, all publications involving the same investigator be carefully analysed for possible fraud, and that readers be warned of the fraudulent results. A quick survey was done of journals, either general with professional editorial teams, or more specialized with unpaid editors, as to their organisation to detect and treat fraud. No clear difference was found between these two types of journals (figure 2). There does not seem to be any clear systematic process to detect fraud, which could concern at least 1-3\% of all scientific publications: $:^{[1]}$ this may seem a small proportion, but since almost 9 million publications were recorded in Medline in 2006, 
as many as 300000 could be fraudulent. Detection of fraud is usually left to the sagacity of the referees or readers.

These are mostly duplicated publications or plagiarism. There is no systematic retractation, i.e. later mentions indication that the publication is fraudulent.

Recommendation:

- install procedures to help referees and editors identify fraud : access to initial research protocol, raw data, ... if there is a suspicion (with protection of confidentiality);

- once fraud is confirmed, retractation of the paper and/or clear identification of paper as fraudulent in databases.

The recent publication of Best Practice Guidelines on publication ethics is freely available. ${ }^{[19]}$

\section{Identification of fraud through registries}

Clinical trials registries with as objective transparency of information, visibility of the adequation of methods and results can limit fraud related to masking or distortion of results. Some already exist, ${ }^{[20,21]}$ others are in preparation : European Eudrapharm registry, French national registry.

Recommendation:

- facilitated procedure to exchange information between registries, for multi-registry searches.

\section{Conclusion}

In conclusion, fraud is a problem that is certainly underestimated and insufficiently treated through lack of adapted prevention, vigilance and exploitation. It can involve all types of studies from their inception to realization to analysis, interpretation or publication. The point that emerged most often was a strong desire to have public procedures to help institutional and private sponsors to detect, manage and prevent fraud. This will be the final common recommendation of this round table.

\section{Participants}

Christophe Baduel (GlaxoSmithKline, Marly le Roi), Corinne Bernaud (AstraZeneca, Rueil Malmaison), Geneviève Chêne (INSERM U 593, Bordeaux), Dominique Doucet (Afssaps, Saint Denis), Thérèse Dupin-Spriet (Faculté Pharmacie, Lille), Valérie Foltzer (Coherences Pharma), Jean-Marie Goehrs (Merck Sharp \& Dohme Chibret, Paris), Danielle Golinelli (Direction Générale de la Santé, Paris), Sylvie Hansel (Hôpital Lapeyronie, Montpellier), Jean-Marc Husson (Eudipharm, Paris),
Pascale Jolliet (Institut de Biologie, Nantes), Rémi LeCoent (GlaxoSmithKline, Marly le Roi), Joël Moret-Bailly (Sainte Foy les Lyon), François Pelen (Pfizer, Paris), Yannick Plétan (Pfizer, Paris), Catherine Rey-Quino (Afssaps, Saint Denis), Jean-Charles Reynier (AP-HM, CHRU, Marseille), Tabassome Simon (Faculté de Médecine Saint Antoine, Paris), Anne-Priscille Vlasto (Leem, Paris), Beat Widler (Hoffmann Laroche AG, Basel, Suisse), Faiez Zannad (CIC, Hôpital Jeanne d'Arc, Dommartin les Toul)

\section{References}

1. Rhodes R, Strain JJ. Whistleblowing in academic medicine. J Med Ethics 2004; 30(1): 35-9

2. Kansu E, Ruacan S. Research ethics and scientific misconduct in biomedical research. Acta Neurochir Suppl 2002; 83: 11-5

3. de Pracontal M. L'imposture scientifique en dix leçons. Paris: Seuil; 2005

4. Lock S, Wells F. Fraud and misconduct in medical research. London: BMJ books; 2002

5. Broad W, Wade N. La souris truquée. Enquête sur la fraude scientifique. Paris: Seuil; 1987

6. Mathews AW. Fraud, errors taint a key study of widely used Sanofi drug; despite some faked results, FDA approves antibiotic; one doctor's cocaine use; company defends safety. Wall St J (East Ed) 2006: A1, A12

7. Couzin J, Schirber M. Scientific misconduct. Fraud upends oral cancer field, casting doubt on prevention trial. Science 2006; 311(5760): 448-9

8. Mathews AW, Wonacott P. Playing detective: at medical journal, editor finds truth hard to track down; termite-eaten data plague Dr. Smith's 12-year probe of an Indian researcher. Wall St J (East Ed) 2005: A1, A2

9. Al-Marzouki S, Roberts I, Marshall T, et al. The effect of scientific misconduct on the results of clinical trials: a Delphi survey. Contemp Clin Trials 2005; 26(3): $331-7$

10. Ranstam J, Buyse M, George SL, et al. Fraud in medical research: an international survey of biostatisticians. ISCB Subcommittee on Fraud. Control Clin Trials 2000; 21(5): 415-27

11. Gardner W, Lidz CW, Hartwig KC. Authors' reports about research integrity problems in clinical trials. Contemp Clin Trials 2005; 26(2): 244-51

12. Safer DJ. Design and reporting modifications in industry-sponsored comparative psychopharmacology trials. J Nerv Ment Dis 2002; 190(9): 583-92

13. Buyse M, George SL, Evans S, et al. The role of biostatistics in the prevention, detection and treatment of fraud in clinical trials. Stat Med 1999; 18(24): 3435-51

14. Al-Marzouki S, Evans S, Marshall T, et al. Are these data real? Statistical methods for the detection of data fabrication in clinical trials. BMJ 2005; 331(7511): 267-70

15. Bostanci A, Vogel G. Research misconduct. German inquiry finds flaws, not fraud. Science 2002; 298(5598): 1531-3

16. DeMets DL. Distinctions between fraud, bias, errors, misunderstanding, and incompetence. Control Clin Trials 1997; 18(6): 637-50; discussion 661-6

17. Nylenna M, Simonsen S. Scientific misconduct: a new approach to prevention. Lancet 2006; 367(9526): 1882-4

18. Dyer O. GP struck off for fraud in drug trials. BMJ 1996; 312 (7034): 798 [letter]

19. http://blackwellpublishing.com/publicationethics/

20. http://www.clinicaltrials.gov

21. http://www.ifpma.org/clinicaltrials

Correspondence and offprints: Nicholas Moore, Département de Pharmacologie, Université de Bordeaux, 33076 Bordeaux Cedex, France.

E-mail: nicholas.moore@pharmaco.u-bordeaux2.fr 